\title{
Exploring excess of deaths in the context of covid pandemic in selected countries of Latin America
}

\author{
Everton E. C. Lima, Estevão Vilela, Andrés Peralta, Marília G. Rocha, Bernardo L. \\ Queiroz, Mario Piscoya Díaz, Marcos R. Gonzaga, Flávio H. M. A. Freire.
}

\section{BACKGROUND}

The covid-19 pandemic has considerably affected the mortality numbers of many countries in the world, and Latin America is now the epicenter of the disease. There is a great demand on analyzing the impact of this new disease in the amount of deaths, but available information of deaths by cause is still lacking in most of the countries in the region. One metric to investigate and analyze the impact of the pandemic is to look at excess mortality.

\section{OBJECTIVE}

We aimed to measure the effects of this disease on mortality levels in selected Latin America countries that were most affected by the covid-19 pandemic, Brazil, Chile, Ecuador and Peru.

\section{METHODS}

Collecting monthly civil registration data, we measured the effects of the pandemic by looking at the excess mortality. We analyzed the effects of the disease on small areas by comparing the mortality levels in 2020 with those of 2019.

\section{RESULTS}

Our findings indicated an excess of deaths initially in major cities and areas, but then is spreading towards inland and at least urbanized areas of each country. We may expect that in the next phase of the pandemic, this illness will probably affect countries' locations in worse socioeconomic and sanitary conditions.

\section{CONCLUSION}

Despite the lack of reliable information, the excess of deaths is a good indicator for measuring the effects of the coronavirus pandemic, especially in the context of Latin America countries, where there is still a lack of good cause of death data. We find strong evidence of the pandemic's impact on mortality levels in all less populated areas affected by this disease.

\section{CONTRIBUTION}

This study provides an initial discussion of the effects of pandemic in small and less urbanized areas of selected countries of Latin America. 


\section{Introduction and background of Covid in Latin America}

In early 2020, several cases of the Covid-19 pandemic emerged in Latin America, following what was observed in Europe and the United States (Rodriguez-Morales et al 2020; Burki 2020; Muñoz 2020). Some empirical evidence indicates that the mortality data for Covid-19 pandemic in countries of Latin America is underreported (Torres and Sacoto 2020; Croda et al 2020). One of the main problems concerning the pandemic is the small amount of tests (Burki 2020; Peto 2020). Overall, Latin America has the lowest test rates in the world, around 63 per 100,000 inhabitants, and expanding tests is one of the most important ways to control the spread of the pandemic. There are also delays between the Covid-19 tests and the time that their results are released, in some cases taking more than two weeks to reveal the outputs (Werneck and Marilia Sá 2020; Bastos et al 2020).

In the case of Brazil, contradicting recommendations from the World Health Organization, Brazilian president has also encouraged people to go out, commonly advocating for relaxing social-distancing measures. Brazil's President primarily regards the virus as "just a little dose of flu". Evaluating the effects of asymmetric information on social distancing, Ajzenman, Cavalcanti and Da Mata (2020) showed that Bolsonaro's words and actions have had a stronger effect on relaxing social distancing in the municipalities of the country, which in turn might increase the spread of infection.

In the case of Peru, the country is the second in South America with the largest coronavirus

infection rate. According to John Hopkins data (https://gisanddata.maps.arcgis.com/apps/opsdashboard/index.html\#/bda7594740fd40 299423467b48e9ecf6), at the end of June it exceeds 300,000 contagions. In addition, the country is the least prepared for this pandemic (Valverde 2020). The international standard ratio of ICU beds per 100,000 inhabitants is 10 beds, and in Peru this number is 2.3 (Valverde 2020).

Like Brazil, the Peruvian case also deserves attention due to the worse management of the crisis by the peruvian government. Even with the imposed lockdown, which started in march 15th, it was observed a fast growing number of deaths by COVID-19 in the country relative to other countries in the region. In addition, the economic resources, obtained by governamental savings from the past decade (later translated into cash transfer programs), have been spent without efficiency and many vulnerable citizens did not get access to these financial resources. Bribery and corruption in almost every public institution lead the country to poor health measures; now we see examples of insufficient oxygen supply for patients in public hospitals (Pierina Pighi Bel e Jake Horton, 2020).

Ecuador was one of the first Latin American countries to be affected by coronavirus with the majority of deaths being reported at Guayaquil in the Guayas province. There is also evidence that the pandemic is spreading towards the least urbanized Ecuador's areas 
(Laberthe 2020; UN 2020). Thus, the mortality explosion in the months of March and April occurred primarily in coastal provinces but epidemic hotspots have gradually moved to the rest of the country.

On April 16, Chile had about 8,807 confirmed cases, less than 200 cases to overcome Italy numbers, when it had to decree total quarantine. Instead of a full quarantine, as an initial strategy and to reduce economic damages, Chile adopted a high number of daily tests, together with local and dynamic quarantines, which depend on the number of active infected. The country also implemented strict measures of social isolation, and follow-up of the infected and the people that he/she has contacted (Kiwi and González, 2020). Despite these measures, as a result, the number of SARS-CoV-2 has substantially increased in the country.

Disregarding each country's situation, the fight against the pandemic in Latin America is more complicated due to data limitations, especially on causes of deaths, and the low number of Covid-19 tests available. In the current crisis, proper information on causes of deaths are crucial to understand the effects of the pandemic. However, one cannot expect that information on causes of deaths will be released very fast, since they need to follow a specific number of procedures that are particular to each country. Even in more developed economies, with mature vital registration programs, there will be a lag in the access of causes of deaths data. It is also important to mention that Latin American countries are becoming the most affected by the SARS-CoV-2 in the world. This region is also characterized by large socioeconomic and regional inequality. In addition to that, there is strong evidence of variation in the data quality in many Latin American countries (Peralta, et.al, 2019b; Queiroz, et.al, 2017, Palloni and Pinto-Aguirre, 2011; Piscoya-Diaz and Queiroz, 2010; Nunes and Icaza, 2006). Thus, one needs to be careful with all the analysis performed here.

Notwithstanding, in the context of a world pandemic, the knowledge of how Covid-19 is affecting mortality and the health status of a population really becomes an important issue for mortality and health studies. However, reliable methods to estimate and project the pandemic impact on the number of deaths (and life expectancy) are still limited or inaccurate. In fact, a clear death toll of the pandemic might take some time to be understood, since proper mortality registration systems do not report real-time data for most of the countries by causes of death (Appleby, 2020; Labib, Arrori, 2020). Also, there are some complicated matters in the definition of mortality by Covid in several places of the world related to underreporting of the cause (Lau et al 2020).

One way to estimate the dynamics of the pandemic and to measure its impact on mortality is by looking at the existing death counts data. Thus, we investigate the overall excess mortality in the year 2020 relative to the number of deaths from previous years. There are 
several reports showing estimates of excess mortality for the country leve ${ }^{1}$, but very few for the subnational level. There are well-suited methods for dealing with this, making it possible to get an idea of how mortality has increased at a given point in time and which ages were the most affected by death numbers (Felix-Cardoso et al 2020; Kontopantelis et al 2020; Krieger et al 2020).

It is important to emphasize that not all excess deaths are due to COVID, but if we observe the excess of deaths, in comparison with previous years, that can work as a good tool to understand trends in lethality of this disease (Nogueira 2020; Adjiwanou et al 2020; Krieger, Chen and Waterman, 2020; Felix-Cardoso, et.al, 2020; Kontopantelis, et.al, 2020). As indicated by Noymer $(2020)^{2}$ and Hellenriger $(2020)^{3}$, we can consider the effect of the epidemic on four types of mortality that are reflected in excess mortality (Adjiwanou et al 2020). First, we have the direct mortality effects, which are the current deaths recorded as Covid-19. Second, the direct-indirect effects that are measured as early deaths in the occurrence of COVID, and that have been mistakenly recorded as influenza or other respiratory illness. The second effect is the subsequent deaths from COVID that are not registered as such. The third effect is indirect mortality. These are deaths from a health problem, which was not treated due to the overload of the health system and intensive care destined to Covid treatment. Finally, we have competitive mortality risks, which represents a person who died due to COVID today, but he/she would have died by other diseases in the near future, caused by another morbidity, that is, Covid-19 is now a competing risk of mortality (Santos \& Howard 2018; Santos et al 2018).

During the course of the pandemic, we will not be able to measure these four effects of this disease but we can access the excess number of deaths. Excess mortality is generally understood as the number of deaths (from any cause of death) that we are seeing in a given time period, subtract or divided by the number of deaths that could occur in the absence of SARS-CoV-2 pandemic (Nogueira, et.al., 2020; Leon, et.al., 2020, Santos-Lozada and Howard, 2018). A central question is how to measure this counterfactual, that is, "what is the number of deaths that could occur in the absence of Covid19"? In most cases, it is calculated either the average number of deaths over a given period in comparison with other recent years, that is, when SARS-CoV-2 did not occur as a cause of death (Adjiwanou et al 2020).

Daily counts of deaths usually come from hospital reports, where they focus on COVID fatalities, and this daily information is passed to Ministries of Health around the globe. Data on overall mortality (that allows to estimate excess mortality) are provided by civil

\footnotetext{
${ }^{1}$ https://www.bbc.com/news/world-53073046; https://ig.ft.com/coronavirus-chart/; https://www.economist.com/graphic-detail/2020/04/16/tracking-covid-19-excess-deaths-across-countries ${ }^{2}$ https://twitter.com/andrewnoymer/status/1241620295095468035

3 https://twitter.com/helleringer143/status/1252580218432348162?lang=en
} 
registrations systems. This is the administrative system that continuously records all deaths. It also includes deaths at home and outside the hospitals, and in many causes they do not report a specific cause of death. To know how many COVID deaths have been counted, we need to wait for the vital statistics publication with cause of death data, and we need to conduct much more refined modeling exercises, and that might take several months.

Several countries around the globe and in Latin America have been collecting monthly mortality data during the development of the pandemic. In the case of Brazil, we have municipality information that is collected via notary offices (administrative records). In the case of Ecuador, the data is provided by civil registers across provinces, making it possible for us to analyze the excess of mortality at less populated areas of both countries. Chile and Peruvian mortality data are collected by partnership of the Ministry of Health and the National Statistical Office.

In this paper, instead of looking at the national level, we focus on smaller areas and look at provinces, capital cities and cities around the capitals for selected countries of the region. There are very few studies, to our knowledge, looking at the sub-national level (Blangiardo et al 2020; Krieger, Chen and Waterman, 2020). If in the first moments of the epidemic, the large volume of deaths was concentrated in places where the first infections were registered; we may expect that throughout the process of spreading, the pandemic is moving to countries' inland directions, hence, it is important to consider the impacts of the pandemic in other areas of the countries.

\section{Data and Methods}

For Brazil, we use data from administrative death records, through death certificates. These data are provided by the Brazilian Civil Registry Offices on the 'Transparency Portal Civil Registry', These data are disaggregated by municipalities in all Brazilian states. The data can be obtained through the link https://transparencia.registrocivil.org.br/registral-covid. From this webpage, the data can be collected only manually, which is a time consuming job in the case of gathering information for all cities with at least fifty cases of Covid-19 in the country. But, we applied data scraping tools to assemble this data in a more efficient way (Mehta, et.al, 2019; Chandrika, et.al, 2020).

As first analysis, we selected 27 Brazilian Metropolitan Areas (MAs) for comparisons. As pointed out by the civil registry system in Brazil, data on the most recent death dates may undergo some changes due to the entry of new records. The procedure for bringing the data into the system may take a few days, and there are corrections made to those events already registered (Fujiwara, 2020). That means, the analysis must be updated and 
adjusted regularly. However, it is important to assess recent trends to observe what has been happening with the dynamics of mortality.

For Ecuador, we use register monthly death civil registers for the year 2020, available at https://www.registrocivil.gob.ec/cifras/. Like Brazil, this data is preliminary, because the database of the Civil Registry Identification and Certification is permanently updated through death registrations made by Ecuadorian citizens.

Peruvian death data is registered by the Ministry of Health, and it is available under request by the link https://www.minsa.gob.pe/defunciones/. We obtain the registered deaths from January 2017 until 01 June 2020. Peruavian death registration is not uniform and the degree of under registration is inversely correlated with the region's economic development (Piscoya \& Queiroz, 2010). The quality of recorded deaths have improved in the last ten years, and the microdata obtained has information about death by place of residence, date of death, age, sex and principal cause of death.

The case of Chile, the death counts data was compiled through data scraping from web page "the tableau public", with free and open access to a broader public by the link: https://public.tableau.com/profile/deis4231\#!/vizhome/HechosVitalesdesdeel2000/Nota Tcnica?publish=yes. This data is connected with the information provided by the Chilean Ministry of Health and National Statistical Office for 346 municipalities of the country. This information is also not free from problems and it is constantly updated by Chilean statistical offices.

For these analyses, we compare the number of the monthly deaths in 2020 relative to the deaths recorded in similar months in 2019, and in some cases to 2018-19. We choose March as the baseline month for all the countries, due to the fact that the first cases of coronavirus detected in Brazil, Chile, Ecuador were on 26, 25 and 29 February 2020, respectively (Brazilian Ministry of Health 2020; Agência Brasil 2020; Comercio 2020). In Peru, the first case was detected on 6 march 2020 (Peruvian Ministry of Health 2020). We compare the average number of deaths, percentage deaths variation and the mortality coefficient of variation in small areas of these countries.

Ideally, information should be broken down into external causes of death, as these may fluctuate from one year to the next (fluctuations in the number of homicides, traffic deaths, etc.). However, these estimates are based on provisional data, which are incomplete. It is important to stress that these data might have several limitations: delay in reporting of events, under-reporting of events and problems in data quality. Thus, the estimates reported here are representing the lower bound of the impacts of the pandemic. 


\section{Results}

For Brazil, in Figure 1, it shows the percentage difference in mortality (death counts) considering all causes of deaths, between 2019 and 2020, for the cumulative months of March and May for each year. We show the results for the major cities and each area without the capital city in these areas. Showing the results this way, allows us to understand whether the pandemic is concentrated in a larger city or it is already spreading for its surrounding minor municipalities.

The findings indicate impressive increases in mortality in many regions of the country. Considering all the 27 regions, only four areas have not shown any increase in the percentage of deaths between the two years (2019 and 2020). In the case of metropolitan capitals, 12 cities stand out, compared to the MAs without its major city. The most expressive differences are found in cities located in the North and Northeast of the country. Here, we give special attention to the municipalities of Recife, Fortaleza Manaus and Belém, where mortality has increased more than 50\% in 2020.

Yet looking at Figure 1, we also see in 10 cases that the excess of mortality in the surrounding municipalities is more noticeable than its capital between 2019 and 2020, which may probably indicate the effects of the pandemic are spreading throughout the country's inland. Once more, in the municipalities in the poorest regions of North Amazon and the seaside Northeast coast of the country, we see this development to a large extent.

Figure 2 shows maps for particular areas of each country. The results show the evolution of deaths in terms of average number and variation coefficient for a selected number of locations, between the two years in study. These selected municipalities give a good geographic overview of the pandemic spread across the country, since it integrates areas from distinguished regions of the country. These cities are also the ones most affected by the beginning of the SARS-CoV-2 pandemic.

When we look at the average differences in mortality, in the two major country cities of São Paulo and Rio de Janeiro, the excess of mortality stands out. In these cities, the differences indicate an average number of more than sixteen hundred deaths occurring solely in the month of March of 2020 in comparison with the previous year.

Important to mention that, both municipalities are located in the most developed region of Southeast of the country, also in terms of health access and facilities. This result is expected, because tourism traffic and business travels, especially from Europe, provided these two cities with the first contacts with the virus. In addition, these are the most populated cities of the country, so it is expected that more people are exposed to death risks. 
Figure 1: Difference, in percent, between the number of deaths registered in 2020 compared to 2019 in the months March to May. Brazilian Metropolitan Areas and Metropolitan Areas without Capital.

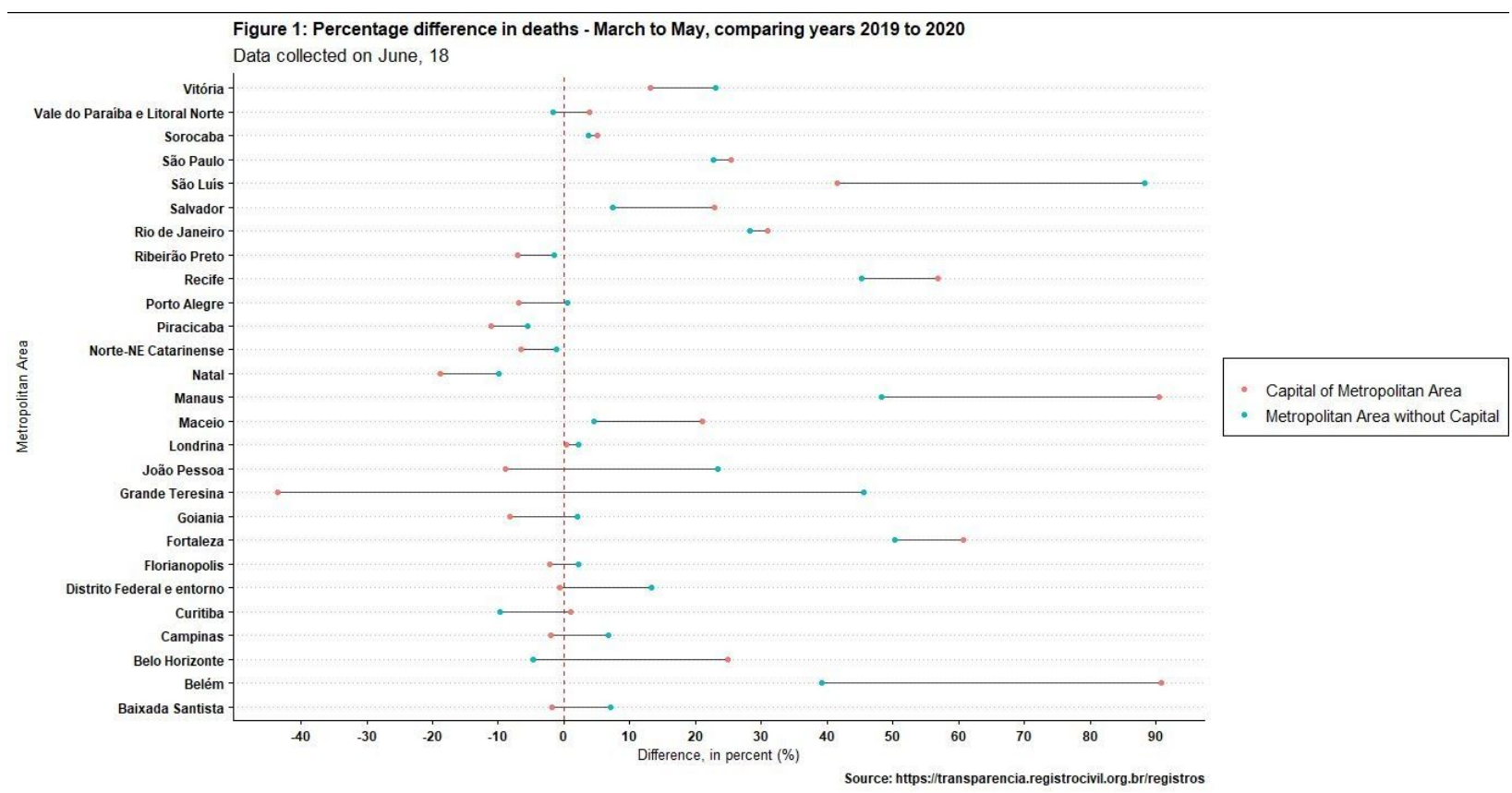

Source: Civil Registers Brazil, 2019 - 2020.

Figure 2: Differences and average deaths and coefficients of variation in selected cities of Brazil. Overall mortality between 2019 and 2020, months March to May.

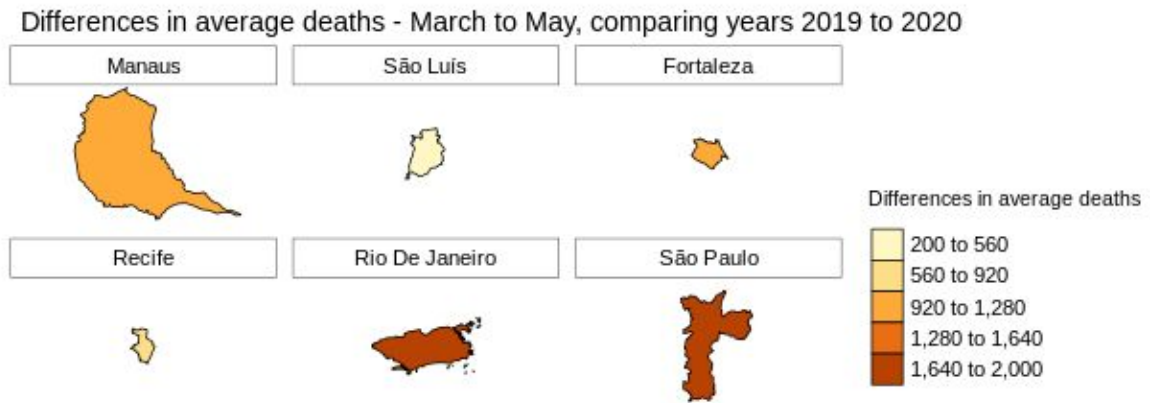

Differences in coefficient of variation of deaths - March to May, comparing years 2019 to 2020

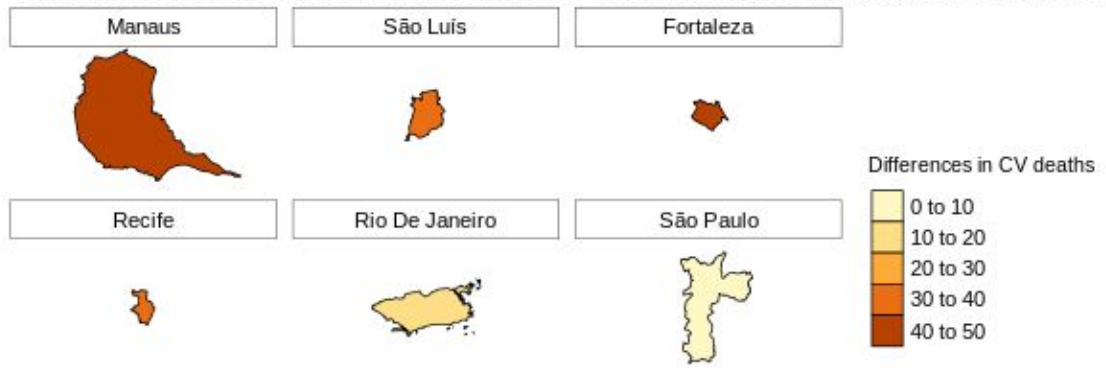

Source: Civil registers Brazil, 2019 - 2020. 
On the other hand, when we pay attention to the variability of deaths, cities from North and Northeast are the ones with distinctive numbers, especially in Manaus (North Amazon) and Fortaleza. Manaus is a good example of a place that, despite being isolated from many other major cities, the pandemic has hard hit the city, and since mid April the number of deaths has increased strongly (Fundação de Vigilância em Saúde 2020). We also believe that this increased heterogeneity in those cities may be related to the Covid-19 pandemic.

Figure 3: Differences and average deaths and coefficients of variation in selected comunas of Chile. Overall mortality between 2019 and 2020, months March to May.

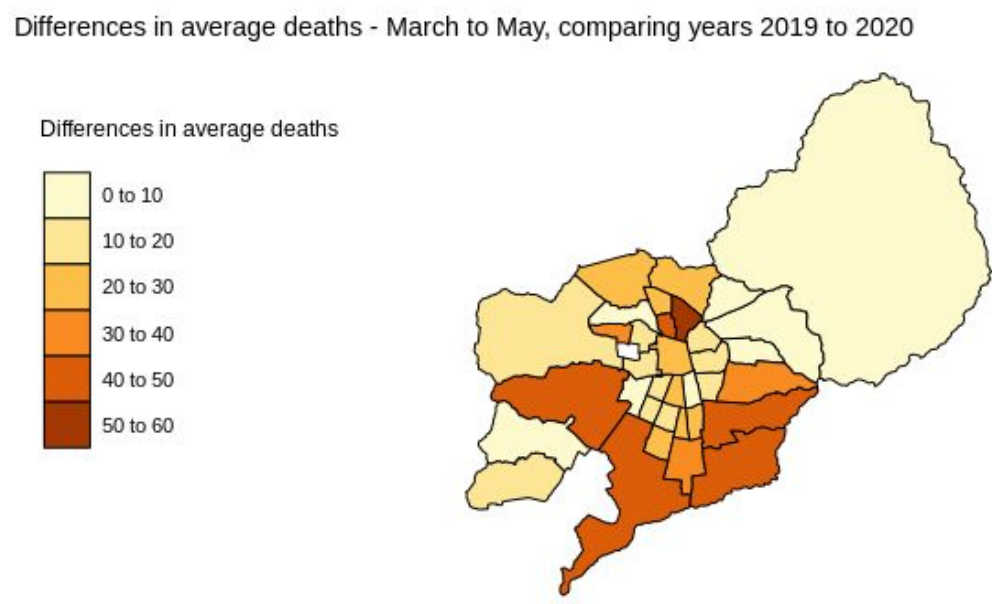

Differences in coefficient of variation of deaths - March to May, comparing years 2019 to 2020

Differences in $\mathrm{CV}$ deaths
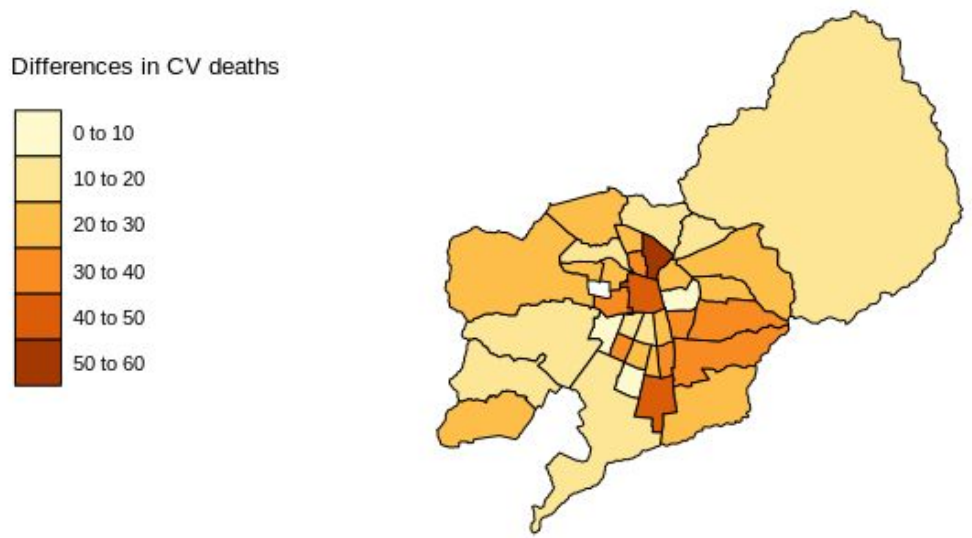

Source: Departamento de Estadisticas e Información de Salud. 2020.

In Chile, in figures 3 and 4, we do not show here results for all 346 municipalities, because data is still being compiled. The findings for the metropolitan area of Santiago present that the most of the excess mortality is observed in major comunas (Santiago city and its surroundings). At the same time, a spatial cluster of excess deaths is also observed in areas more distant from the country's capital. But higher variability in the number of deaths are still located in the comuna of Santiago. 
The pandemic has been monitored since March 3 2020, when the first person infected with COVID-19 was notified. Until April 12 2020, the Ministry of Health (MINSAL) has reported 7,525 infected people and 82 deaths, concentrating the largest number of cases in the Metropolitan Santiago, Araucanía, Biobío and Ñuble regions.

Word of caution is necessary in the case of Chile. In relation to the recovered COVID-19 cases, there is controversy in the records due to the criteria used by the Ministry of Health, which establishes as recovered from the disease any person who completes 14 days from the COVID-19 confirmation and does not present any symptoms after that days duration, and is found in good health (Guerrero-Nancuante \& Manríquez, 2020). This fact in turn may also affect the number of death records by this illness.

Figure 4: Difference, in percent, between the number of deaths registered in 2020 compared to 2019 in the months March to May. Selected comunas of Chile.

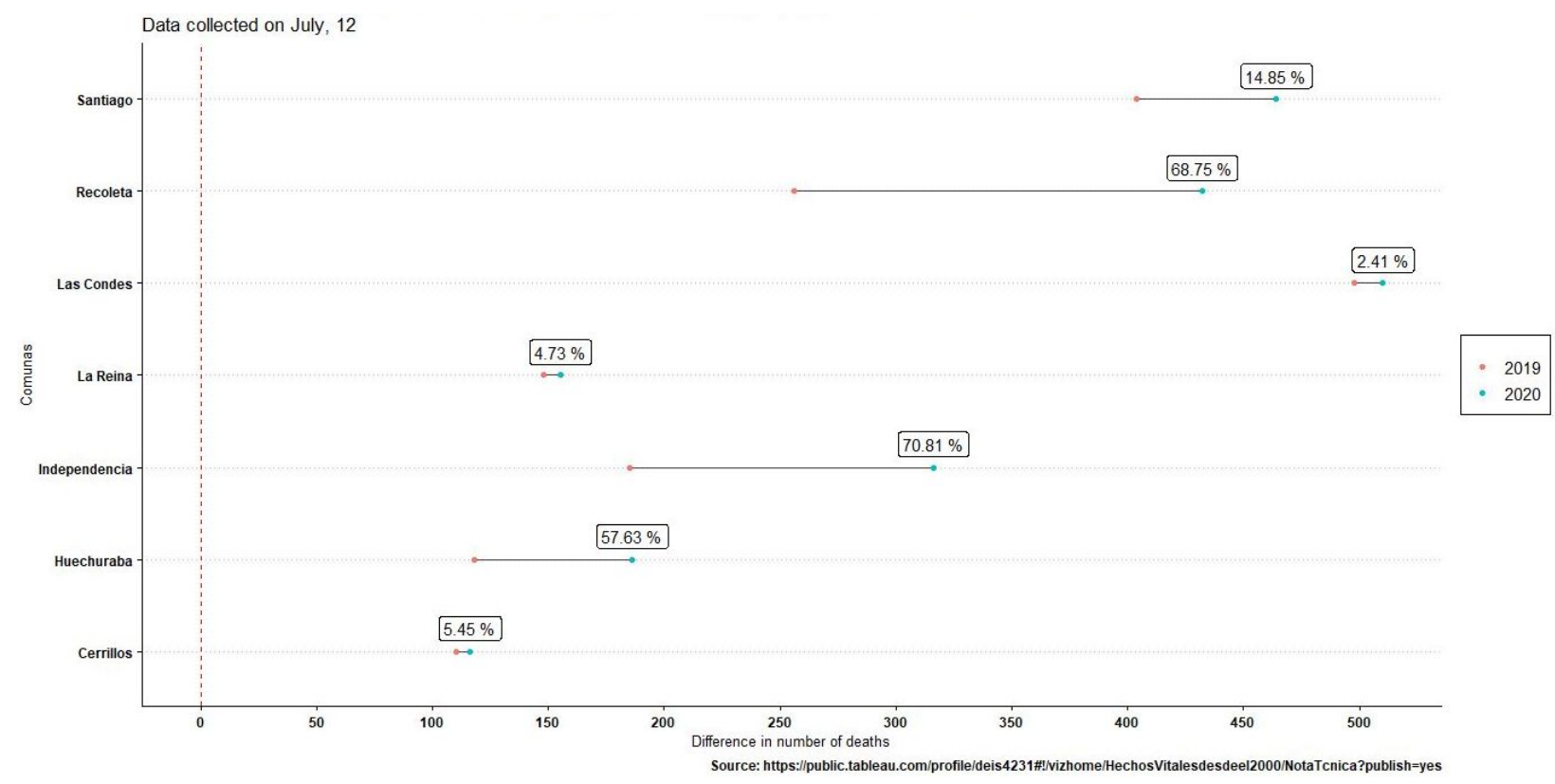

Source: Departamento de Estadisticas e Información de Salud. 2020.

In the case of Ecuador, Figure 5, we also see the effects of excess deaths, especially in the region of Guayas, where the port of Guayaquil is located. It is important to mention that mortality explosions occurred in the months of March and April first in coastal provinces, but the epidemic and mortality hotspots have gradually moved to the rest of the country.

In figure 6, in the province of Pichincha, where the capital city of Quito is located, the amount of deaths is steadily increasing since March. Moreover, the highest levels of excess mortality are also observed in other Western parts of the country. As Peralta et.al (2019a) mention, the most socioeconomic deprived cantons of the country are located in the Amazon, Central Andean, and Northern and Central coastal regions. 
Figure 5: Differences in percentages of deaths in Ecuador. Overall mortality in 2020 in relation to 2019, months January to May.
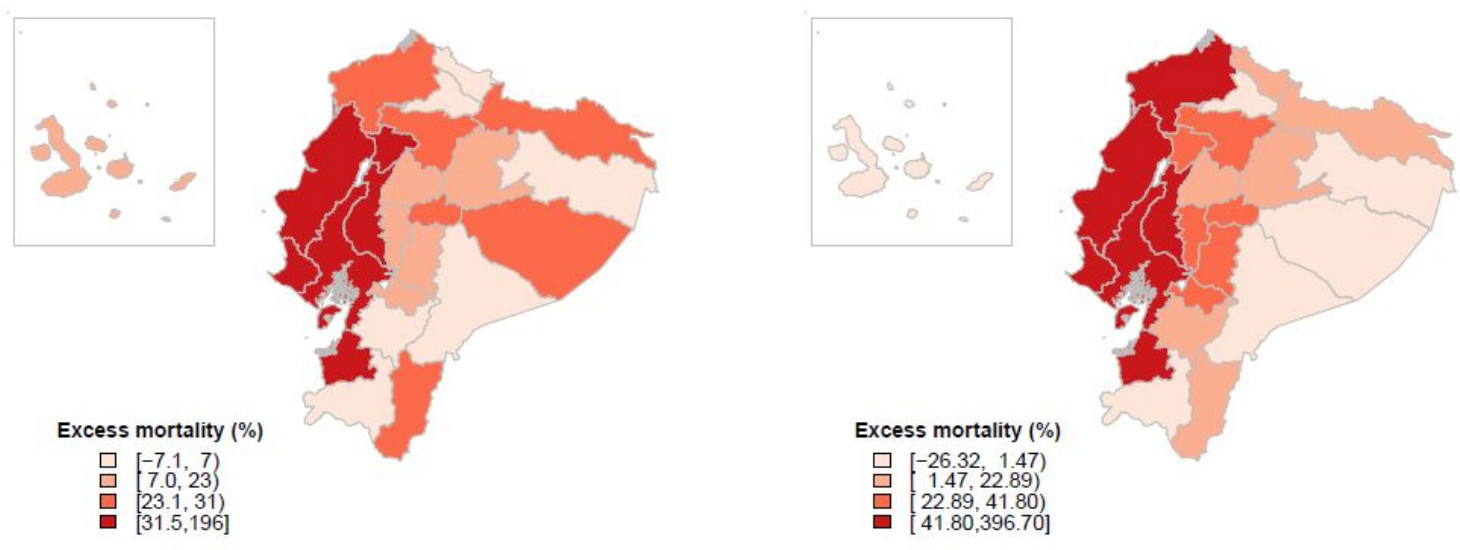

Source: Ecuador, https://www.registrocivil.gob.ec/cifras/, 2020.

Figure 6: Temporal evolution of excess mortality in the selected departments of Ecuador, Jan-June, 2018 to 2020.
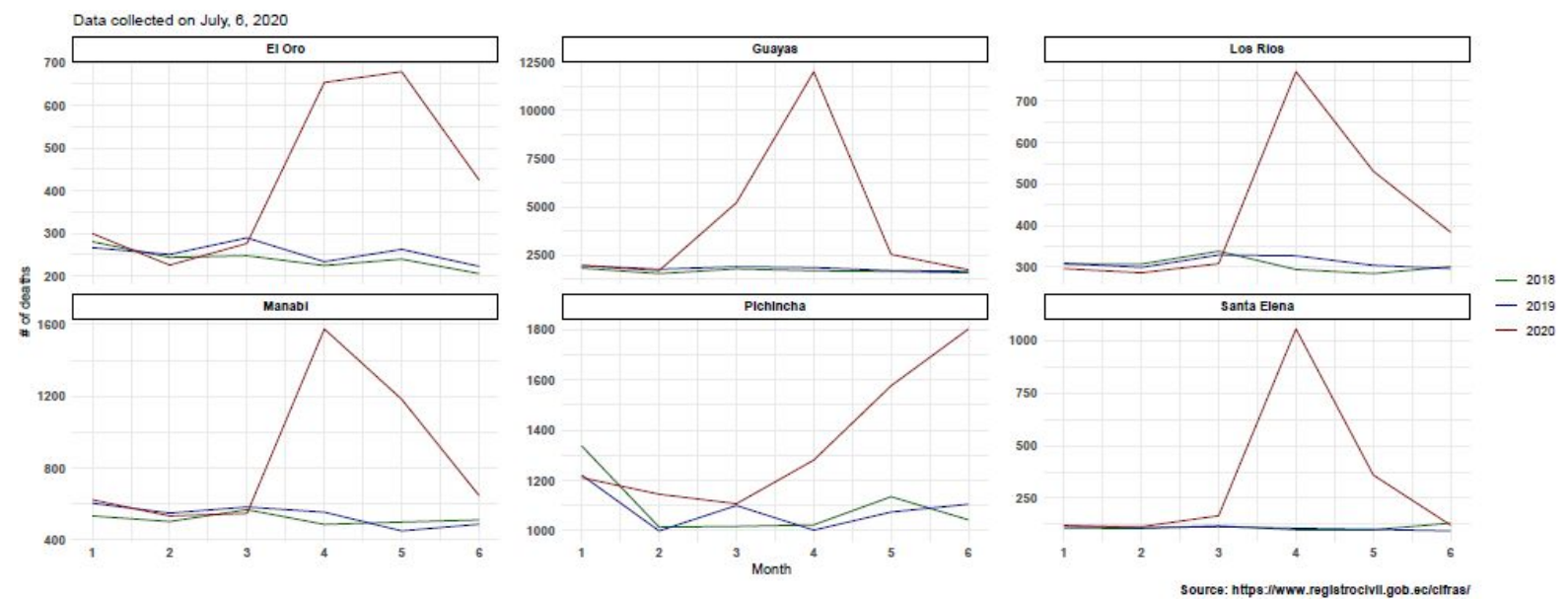

Source: Ecuador, https://www.registrocivil.gob.ec/cifras/, 2020.

For example, the city of Guayaquil is composed of millions of inhabitants, characterized by enormous inequalities; a city where the climate at this time of year is especially harsh due to the high temperatures and other discomforts typical of the time. The city also lacks adequate drinking water sources, and $60 \%$ of people do not have access to internet, which 
in turn makes it difficult to impose lockdown, because many people cannot work or study remotely (Acosta 2020).

In the case of Peru, we observed a considerable increase in the number of deaths, when we compare the months of March - May 2019 with the same period in 2020. The overall percentage variation is $63.5 \%$ more mortality for the entire country. However, the increase in the number of deaths is not uniform spread across Peru. For example, the region of Lambayeque is the peruvian department where there was the largest difference in observed average number of deaths, which passed from 55.67 in 2019 to 321.33 in 2020, indicating deaths increasing by $477.25 \%$ in that period. Ucayali, located in the Amazon region, has registered an increase of $163.30 \%$ in the average number of deaths in that period, followed by Callao with $155.21 \%$ more deaths in 2020. In addition, in the country's capital Lima and the poor region of Loreto, both have registered deaths' increase of 154,01\% between 2019 and 2020.

Figure 7. Differences in mortality in Peru between 2019 e 2020 Comparison of observed total deaths occurred in March - May by region.

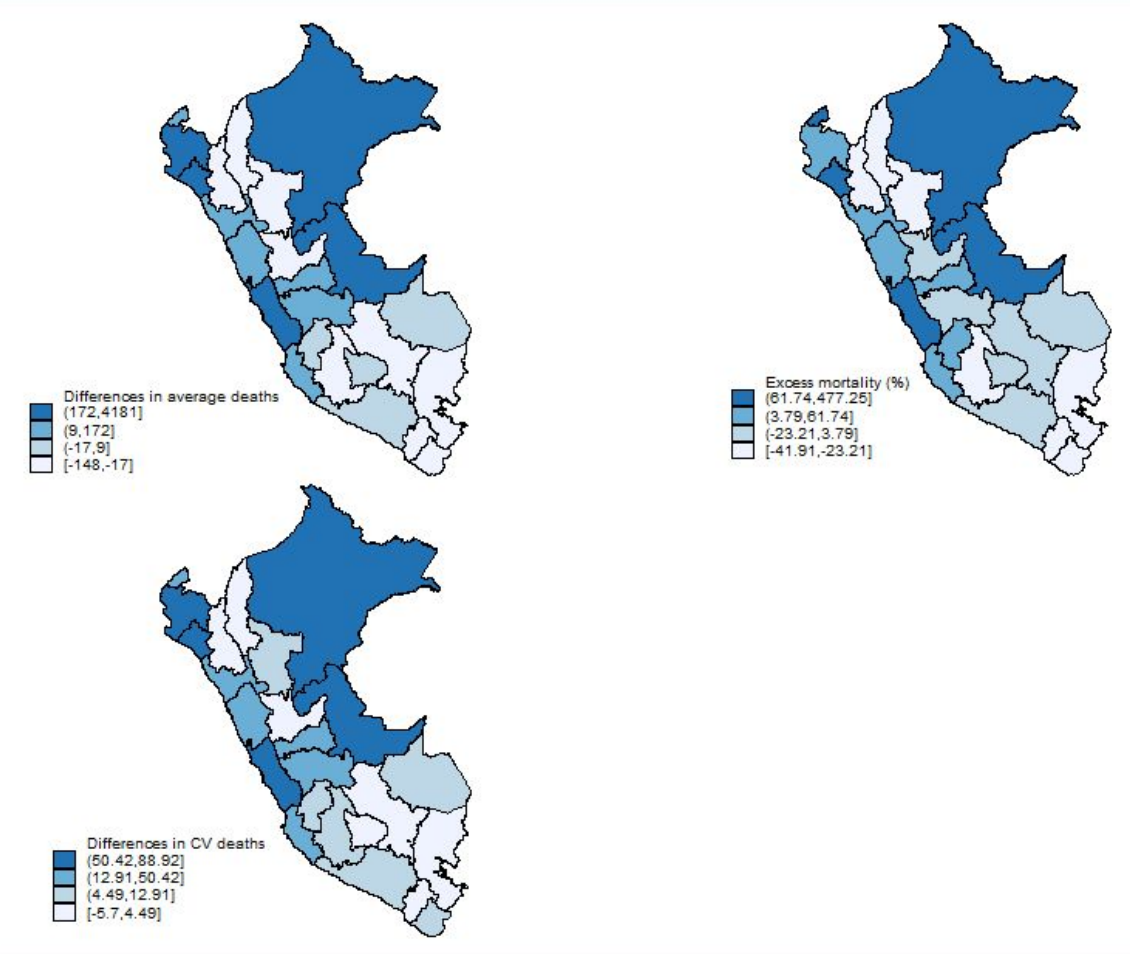

Source: Peru, https://www.minsa.gob.pe/defunciones/2 2020.

The coefficients of variation (CV), for the total of deaths registered between March - May of each year, also indicate higher values in 2020 relative to the previous year, meaning that there is a great variation in the number of deaths observed in March, April and May in the year 2020. In order to illustrate that, let's consider the case of Lambayeque, which 
registered a CV of $94.11 \%$ in 2020 , and this value was only $5.5 \%$ in 2019 . The same increase in deaths' heterogeneity is observed in the most of peruvian regions. For example, in Lima and Loreto, the CV's have shifted, respectively, from $5.26 \%$ to $58.17 \%$ and $2.31 \%$ to $74.32 \%$ between 2019 and 2020 .

The average increase in total number of deaths can also be observed inside the lesser disaggregated regions of Peru. Lima is, for instance, the region that accounts for almost $30 \%$ of peruvian inhabitants, and it is divided into 43 subregions called districts. As we see in Figure 8, we see that in some districts the excess mortality is more than $200 \%$. These locations are specially the ones located in the worse socioeconomic parts of Lima city.

Figure 8. Differences in mortality in Lima and Callao between 2019 e 2020 Comparison of observed total deaths occurred in March - May by district.

Lima and Callao

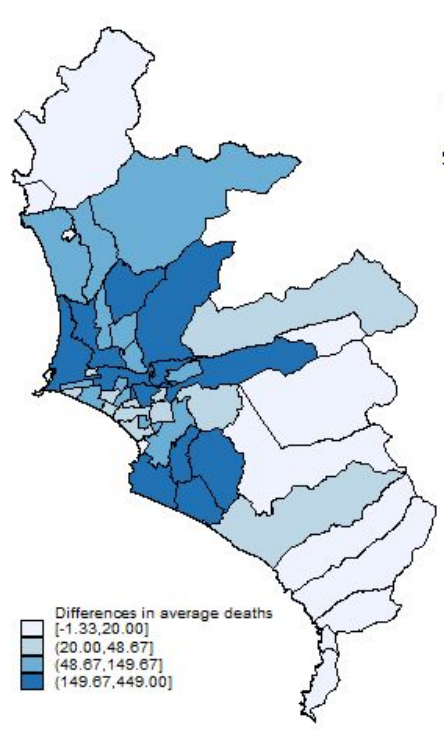

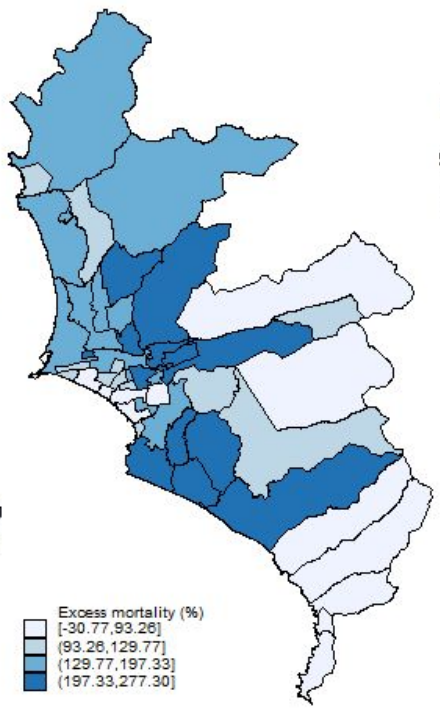

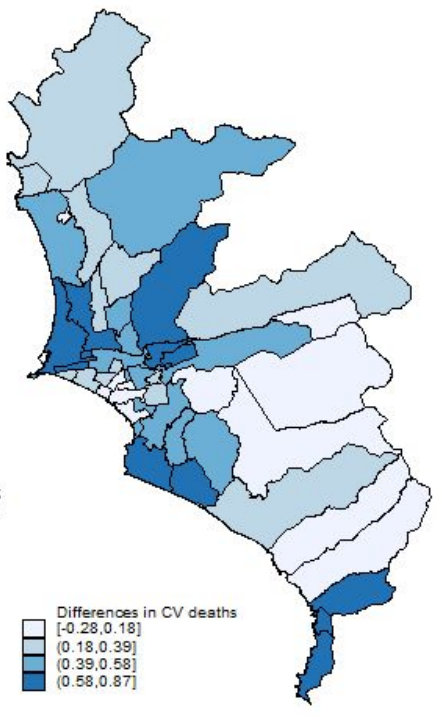

Source: Peru, https://www.minsa.gob.pe/defunciones/, 2020.

\section{Discussion}

In the end, the excess mortality from all causes is an important indicator of the magnitude of the health crisis, much better than the hospital count of cases and deaths due to COVID. That has been shown in the results comparing the developments of total mortality in small areas of four Latin American countries, during the months of March-May (March-April 2020 in the case of Ecuador) from the years 2019 and 2020. 
The mortality trend analysis, allows us to indicate that we are not going through a normal moment, and it is not a simple flu outbreak. Therefore, during the pandemic, with everything else equal, we should not expect more deaths from other causes throughout the year, because now people may be dying from Covid. In other words, Covid has now become a competitive risk. But in addition, we will have the effects of direct-indirect mortality (the poorly classified ones) and indirect mortality.

In these early moments of social isolation, in fact, the COVID-19 containment measures may also affects overall mortality rates due to impacts such as reduced road accidents (if mobility reduces during lockdown) and violence (homicides), increased femicide (if domestic violence spiked during quarantine), or increased deaths due to other health-related issues, if hospitals became overwhelmed and health-seeking behavior changed (Lopez-Calva 2020). But, the current database does not yet allow us to observe this, since the Civil Registry does not disclose the causes with this level of detail so quickly. On the other hand, the rate at which people die from other causes may increase also due to greater difficulty in accessing health services, less health care, increased stress due to isolation and other things.

In all four countries analyzed, the number of total deaths initially increased in the most developed and urbanized regions, but more recent data shows that mortality is starting to spread inland, and it is also affecting the less developed regions of all countries studied. Though, we need to interpret these numbers with caution, because we do not know the true degree of deaths underreporting in these areas (Lopez-Calva 2020), and the accurate reporting of COVID-19 mortality also lacks, that fact can also compromise the results.

It is essential, however, that this analysis is constantly updated. The data evaluated and analyzed carefully. The main caveat of the analysis is the quality of information, but all the estimates indicate very high levels of excess mortality, despite data limitations. It is also important that the agencies release the data in as much detail as possible: sex, age, causes of death, allowing health managers to monitor the potential effect of the epidemic on the general health of the population. As Lopez-Calva (2020) mentions, to combat COVID-19, it is important that we know the true extent of the challenge that we are facing. 


\section{References}

Acosta, A 2020. EL CORONAVIRUS EN LOS TIEMPOS DEL ECUADOR. https://www.fundacioncarolina.es/wp-content/uploads/2020/04/AC-23.-2020.pdf.

Adjiwanou, V., Alam, N., Alkema, L., Asiki, G., Bawah, A., Béguy, D., ... You, D. (2020, May 19). Measuring excess mortality during the COVID-19 pandemic in low- and lower-middle income countries: the need for mobile phone surveys. https://doi.org/10.31235/osf.io/4bu3q

Agência Brasil (2020). No primeiro caso da doença no Chile, coronavírus atinge médico. https://agenciabrasil.ebc.com.br/internacional/noticia/2020-03/no-primeiro-caso-da-doe nca-no-chile-coronavirus-atinge-medico.

Ajzenman, N., Cavalcanti, T. \& Da Mata, D. (2020). More than Words:Leaders' Speech and Risky Behavior During a Pandemic. Pre-print version, available at: http://iepecdg.com.br/wp-content/uploads/2020/04/ACDM 4 2020-1.pdf.

Appleby J. What is happening to non-covid deaths?. bmj. 2020 Apr 24;369.

Barreto, M. L., Barros, A. J. D. D., Carvalho, M. S., Codeço, C. T., Hallal, P. R. C., Medronho, R. D. A., ... \& Werneck, G. L. (2020). O que é urgente e necessário para subsidiar as políticas de enfrentamento da pandemia de COVID-19 no Brasil?

Bastos, Leonardo Soares, et al. "COVID-19 e hospitalizações por SRAG no Brasil: uma comparação até a 12aㅗ semana epidemiológica de 2020." Cadernos de Saúde Pública 36 (2020): e00070120.

Blangiardo M, Cameletti M, Pirani M, Corsetti G, Battaglini M, Baio G. Estimating weekly excess mortality at sub-national level in Italy during the COVID-19 pandemic. medRxiv. 2020 Jan 1.

Bengtsson, Tommy, Martin Dribe, and Björn Eriksson. "Social class and excess mortality in Sweden during the 1918 influenza pandemic." American journal of epidemiology 187.12 (2018): 2568-2576.

Burki, T. (2020). COVID-19 in Latin America. The Lancet Infectious Diseases, 20(5), 547-548.

Chandrika, G. N., Ramasubbareddy, S., Govinda, K., \& Swetha, E. (2020). Web scraping for unstructured data over the web. In Embedded Systems and Artificial Intelligence (pp. 853-859). Springer, Singapore.

Comercio, El (2020). Ministra de Salud confirma primer caso de coronavirus en Ecuador. https://www.elcomercio.com/actualidad/salud-confirma-primer-caso-coronavirus.html. Accessed 19 June 2020. 
Croda, J., Oliveira, W. K. D., Frutuoso, R. L., Mandetta, L. H., Baia-da-Silva, D. C., Brito-Sousa, J. D., ... \& Lacerda, M. V. G. (2020). COVID-19 in Brazil: advantages of a socialized unified health system and preparation to contain cases. Revista da Sociedade Brasileira de Medicina Tropical, 53.

Dale, Becky \& Stylianou, Nassos (2020) - Coronavirus: what is the true death toll of the pandemic?. Available at: https://www.bbc.com/news/world-53073046. Retrieve on 20/06/2020.

de Oliveira Andrade Rodrigo. Covid-19: Concerns rise as cases expand rapidly in South America BMJ 2020; 369 :m1926.

Fundação de Vigilância em Saúde (2020). Painel Covid 19 Amazonas. http://www.saude.am.gov.br/painel/corona/ Accessed 18 June 2020.

Felix-Cardoso J, Vasconcelos H, Rodrigues P, Cruz-Correia R. Excess mortality during COVID-19 in five European countries and a critique of mortality analysis data. medRxiv. $2020 \operatorname{Jan} 1$.

Fujiwara, Thomas (2020). Estimating Excess Deaths due to Covid-19 in Brazil using the Cartorios ' Data. Notes on slides. Available at: https://www.princeton.edu/ fujiwara/ . Retrieved on 20/06/2020

Ghislandi, Simone, et al. "News from the front: Estimation of excess mortality and life expectancy in the major epicenters of the COVID-19 pandemic in Italy." medRxiv (2020).

Haro, A. S. (2020). CARACTERIZACIÓN EPIDEMIOLÓGICA DE COVID-19 EN ECUADOR. InterAmerican Journal of Medicine and Health, 3, 1-7.

Helleringer, S. (2020). A thread on the measurement of excess mortality and uncounted COVID19 deaths. Key point: be careful inferring the number of uncounted COVID19 deaths from a look at all-cause mortality data. https://twitter.com/helleringer143/status/1252580218432348162?lang=en

Kiwi and González (2020). COVID-19: Chile no está aplanando la curva, la perdimos de vista.

https://www.uchile.cl/noticias/162613/covid-19-chile-no-esta-aplanando-la-curva-la-per dimos-de-vista.

Kontopantelis E, Mamas MA, Deanfield J, Asaria M, Doran T. Excess mortality in England and Wales during the first wave of the COVID-19 pandemic. medRxiv. 2020 Jan 1.

Krieger N, Chen JT, Waterman PD. Excess mortality in men and women in Massachusetts during the COVID-19 pandemic. The Lancet. 2020 May 27.

Laberthe, S. 2020. ¿Qué pasa en Ecuador? Covid-19, crisis sanitaria y conflictividad política. https://nuso.org/articulo/que-pasa-en-ecuador/ 
Labib PL, Aroori S. Expanding the definition of covid-19 deaths will show the true effect of the pandemic. bmj. 2020 May 29;369.

Lau, H., Khosrawipour, T., Kocbach, P., Ichii, H., Bania, J., \& Khosrawipour, V. (2020). Evaluating the massive underreporting and undertesting of COVID-19 cases in multiple global epicenters. Pulmonology.

López-Calva, Luis Felipe. A greater tragedy than we know: Excess mortality rates suggest that COVID-19 death toll is vastly underestimated in LAC https://www.latinamerica.undp.org/content/rblac/en/home/presscenter/director-s-grap h-for-thought/a-greater-tragedy-than-we-know--excess-mortality-rates-suggest-t.html

Mehta, K., Salvi, M., Dand, R., Makharia, V., \& Natu, P. (2020). A Comparative Study of Various Approaches to Adaptive Web Scraping. In ICDSMLA 2019 (pp. 1245-1256). Springer, Singapore.

Ministry of Health (2020). Brasil confirma primeiro caso da doença. Available at: https://www.saude.gov.br/noticias/agencia-saude/46435-brasil-confirma-primeiro-casode-novo-coronavirus. Accessed in 17 June 2020.

Muñoz, N. (2020). COVID-19 in Latin America: a first glance at mortality. Colombia Médica, 51(2).

Navarro, J. C., Arrivillaga-Henríquez, J., Salazar-Loor, J., \& Rodriguez-Morales, A. J. (2020). COVID-19 and dengue, co-epidemics in Ecuador and other countries in Latin America: Pushing strained health care systems over the edge. Travel Medicine and Infectious Disease.

Nogueira, Paulo Jorge, et al. "Excess mortality estimation during the COVID-19 pandemic: preliminary data from Portugal." Acta Médica Portuguesa 33.13 (2020).

Noymer, Andrew (2020). At the population level, there will be FOUR TYPES of COVID19 mortality. Tread available at: https://threadreaderapp.com/thread/1241620288825167874.html. Accessed 17 June 2020.

Núñez, ML F., and MG N. Icaza. "Quality of Mortality statistics in Chile, 1997-2003." Revista medica de Chile 134.9 (2006): 1191-1196.

Olson, Donald R., et al. "Preliminary estimate of excess mortality during the COVID-19 outbreak-New York City, March 11-May 2, 2020." (2020).

Palloni, A., \& Pinto-Aguirre, G. (2011). Adult mortality in Latin America and the Caribbean. In International handbook of adult mortality (pp. 101-132). Springer, Dordrecht.

Peralta, Andrés, et al. "Studying geographic inequalities in mortality in contexts with deficient data sources: lessons from Ecuador." Epidemiology 31.2 (2020): 290-300. 
Peralta, A., Espinel-Flores, V., Gotsens, M., Pérez, G., Benach, J., \& Marí-Dell'Olmo, M. (2019a). Developing a deprivation index to study geographical health inequalities in Ecuador. Revista de Saúde Pública, 53, 97.

Peralta, A., Benach, J., Borrell, C., Espinel-Flores, V., Cash-Gibson, L., Queiroz, B. L., \& Marí-Dell'Olmo, M. (2019b). Evaluation of the mortality registry in Ecuador (2001-2013)-social and geographical inequalities in completeness and quality. Population health metrics, 17(1), 3.

Peto, J. (2020). Covid-19 mass testing facilities could end the epidemic rapidly. Bmj, 368.

Piscoya-Díaz, M., \& Queiroz, B. L. (2010). What do we know about adult mortality and data quality in Peru? Mortality coverage levels and trends from recent decades. Papeles de Población, 16(63), 219-241.

Queiroz, B. L., Freire, F. H. M. D. A., Gonzaga, M. R., \& Lima, E. E. C. D. (2017). Completeness of death-count coverage and adult mortality (45q15) for Brazilian states from 1980 to 2010. Revista Brasileira de Epidemiologia, 20, 21-33.

Rodriguez-Morales, A. J., Gallego, V., Escalera-Antezana, J. P., Méndez, C. A., Zambrano, L. I., Franco-Paredes, C., ... \& Risquez, A. (2020). COVID-19 in Latin America: The implications of the first confirmed case in Brazil. Travel medicine and infectious disease.

Santos-Lozada, Alexis R., and Jeffrey T. Howard. "Use of death counts from vital statistics to calculate excess deaths in Puerto Rico following Hurricane Maria." Jama 320.14 (2018): 1491-1493.

Santos-Burgoa, C., Sandberg, J., Suárez, E., Goldman-Hawes, A., Zeger, S., Garcia-Meza, A., ... \& Andrade, E. (2018). Differential and persistent risk of excess mortality from Hurricane Maria in Puerto Rico: a time-series analysis. The Lancet Planetary Health, 2(11), e478-e488.

Torres, Irene and Sacoto, Fernando . "Localising an asset-based COVID-19 response in Ecuador." The Lancet 395.10233 (2020): 1339.

United Nations 2020. PLAN DE RESPUESTA HUMANITARIA COVID-19 ECUADOR. 44p.

Valverde, J. (2020) "COVID-19 en Perú: "Estamos lastimados, como médicos, como seres humanos". Available

in: https://www.dw.com/es/covid-19-en-per\%C3\%BA-estamos-lastimados-como-m\%C3\%A 9dicos-como-seres-humanos/a-53490240.

Werneck, Guilherme Loureiro, and Marilia Sá Carvalho. "A pandemia de COVID-19 no Brasil: crônica de uma crise sanitária anunciada." (2020): e00068820. 